\title{
ASSESSING AND MODELING THE READINESS OF ELECTRONIC GOVERNMENT
}

\author{
Shin-Ping Liu Tucker \\ University of Wisconsin-Superior \\ UW-Superior, Swenson 3025, 801 N 28th Street, Superior, WI 54880 \\ stucker5@uwsuper.edu
}

\begin{abstract}
The purpose of this study is to assess various instruments, including Information System Assessment (ISA), Information Technology Governance (ITG), and Organization Information System Alignment (IS-ALIGN) to examine their ability to measure the readiness of electronic government. The E-Government (EGOV) instrument was adapted from the study of the Action-Audience Model to measure how well the government is prepared to usher in E-Government in terms of various success factors at the planning, system and data levels. An on-line survey was conducted in Denton, Texas. An invitation letter of the survey was sent out to the 1100 employees of the City of Denton via email, 339 responses were received, yielding a response rate of $31 \%$. Although the modified models were in line with the theoretical hypotheses, the confirmation of the relationships among the constructs still needs researchers to pursue more reliable models, either by replication of this research or by establishing a new theoretical model. However, the significant validity and reliability measures discussed in this study indicate that the instrument of this E-Government readiness model has the potential for use in further adoption studies.
\end{abstract}

Keywords: Electronic Government, E-Government, E-Government Readiness Model

\section{INTRODUCTION}

Internet technology has dramatically changed how individuals and businesses relate to their government, creating an evolution in expectations. Electronic government (E-Government) is a way for governments to use new technologies to provide people with convenient access to government information and services, to improve the quality of the services and to provide greater opportunities to participate in the democratic institutions and processes. The promise of E-Government is quickly becoming a reality. 
E-Government is no longer merely an option; it is inevitable ${ }^{1}$. For government, the question now is not whether they are going to provide electronic services, but how and when ${ }^{2}$.

This study will concentrate on E-Government readiness to embrace information technology (IT) by using technology integration and business alignment as a foundation for assessment. This study will also propose an E-Government readiness model that helps organizations maximize the benefits derived from their IT by more completely understanding the interplay between IT and the rest of the organization. The E-Government readiness model will allow an exploration of the relationships among information systems (IS) structure, organizational structure and readiness for E-Government. In particular, the readiness model will assist an organization that would like a comprehensive baseline assessment and assistance in developing strategies for long-term improvements.

In terms of these comprehensive baseline needs of the relationships among IS structure, organizational structure and readiness for E-Government, this study is first of all an examination of information quality, system quality, and service quality - and their effects on IS use, user satisfaction, and how they ultimately form various impacts upon the organizational IS structure. Secondly, the study examines how an organization manages its objectives for IT to enhance the government's readiness and move forward with E-Government. Thirdly, the study examines the types and degrees of alignments among subsystems of the organizational operations and the processes by which IT decisions are made and implemented. Finally and most importantly, this study examines the organizational readiness for providing E-Government capabilities to accomplish its E-Government initiatives, including measures of the readiness of the organization, its employees, and technology.

\section{LITERATURE REVIEW AND THEORY BACKGROUND}

This study examines and compares several assessment instruments: an information system assessment (ISA) instrument based on IS-SERVQUAL as proposed by Van Dyke, Kappelman, and Pybutok ${ }^{3,4}$, and the theory of IS Success Model ${ }^{5}$; an assessment instrument of organizational structure based on the theory of IT governance and an instrument based on Malcolm Baldrige National Quality Award ${ }^{6}$; and an E-Government assessment instrument based on the Three-Ring Model of the Internet integration strategy framework as proposed by Koh and Balthazard. ${ }^{7}$ Subsequently, there are four potential constructs in the study-including both IS-SUCCESS and IS-SERVQUAL combined and referenced as IS assessment (ISA) in the IS structure in this study; IT governance (ITG) and 
organization-IS alignment (IS-ALIGN) separately in the organizational structure; and readiness for E-Government (EGOV).

The IS Success Model and IS-SERVQUAL constitute the theoretical framework of IS assessment (ISA) in the study, which attempt to measure system quality, information quality, service quality, IS use, user satisfaction, and ultimately producing some impacts within an organization. The ISA assessment (ISA) of this study corresponds to a revised model of DeLone and McLean's ${ }^{5}$ IS Success model that has a new dimension added: service quality (which also conforms to Myers, Kappelman, and Prybutok's ${ }^{8}$ suggested modifications and refers as the Comprehensive IS Assessment Model). DeLone and McLean's IS Success model ${ }^{5}$ employs an IS-specific perspective and reflects the relationships of six IS Success dimensions (i.e., system quality, information quality, use, user satisfaction, individual impact, and organizational impact). DeLone and McLean's model is regarded as a comprehensive IS assessment model in the IS domain. The IS-SUCCESS instrument in the study was invented by Kappelman and Chong'. SERVQUAL ${ }^{10}$ is a popular instrument for measuring service industries such as banking and credit card processing. Van Dyke, Kappelman, and Prybutok $^{4}$ proposed a modified version of an IS service quality instrument. This proposed IS-SERVQUAL instrument measures the service quality of an IS provider or IS support team in the organization.

The IT governance (ITG) instrument helps meet the multiple needs of management by bridging the gaps among business risks, control needs and technical issues. The ITG instrument, invented by Sanchez and Kappelman $^{11}$, is based on the framework of Control Objectives for Information and related Technology ${ }^{12}$. The COBIT framework contains a set of control objectives and is grouped into four domains: planning and organization, acquisition and implementation, delivery and support, and monitoring. This structure covers all aspects of information and the technology that supports ITG. IT governance in the COBIT framework integrates IT performance in a manner that allows maximizing benefits, capitalizing on opportunities, and gaining competitive advantage ${ }^{12}$.

The Strategic Alignment Model $\left(\mathrm{SAM}^{13}\right)$ and the Malcolm Baldrige National Quality Award ${ }^{6}$ constitute the theoretical frameworks on which the IS-ALIGN questions were based. The IS-ALIGN instrument, invented by Sanchez and Kappelman ${ }^{14}$, addresses both how IT is in harmony with the business, and how the business should, or can be, in harmony with $\mathrm{IT}^{14}$. IS-ALIGN measures how the functions of IT relate to organization functions. MBNQA provides an organization-wide perspective and provides a foundation for the IS-ALIGN instrument questions. The framework of MBNQA contains three basic elements: (1) strategy and action plans, (2) system (including dimensions of leadership, strategic planning, customer 
and market focus, human resource focus, process management, and business results), and (3) information and analysis.

The theoretical framework of E-Government (EGOV) represented by the Three-Ring Model of the Internet integration strategy framework as proposed by Koh and Balthazard ${ }^{6}$ also underlies this study. Koh and Balthazard $^{7}$ investigate how organizations integrate different Internet applications into a coherent and effective business tool at three different levels: (1) the business planning level, (2) the system management level, and (3) the data infrastructure level. The E-Government readiness (EGOV) instrument based on the Three-Ring Model in this study is assessed at three levels: planning, system, and data levels. The objective of this study is to measure the readiness of the organization, its employees, and technology to accomplish its E-Government initiatives. The E-Government readiness model allows for an exploration of the relationships among IS structure (DeLone and McLean's IS Success model and IS-SERVQUAL), organizational structure (ITG and IS-ALIGN), and readiness for E-Government (EGOV). This study focuses on the readiness for E-Government to embrace IT by using technology integration and business alignment as a backdrop.

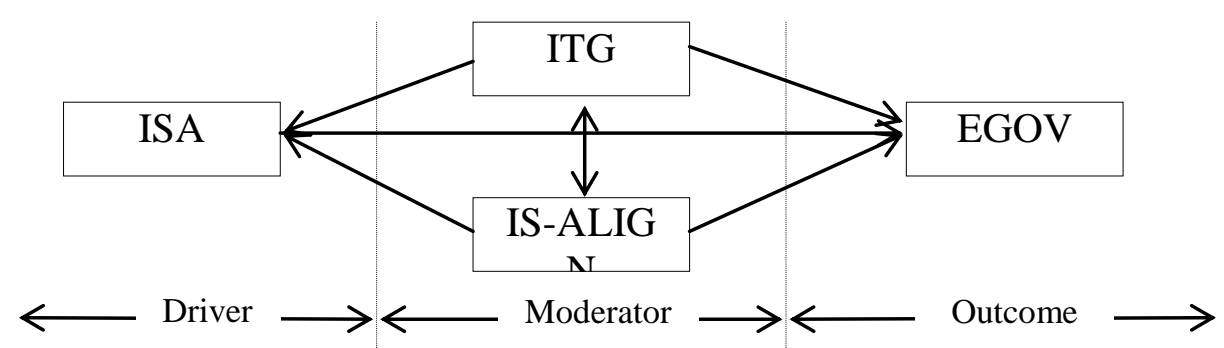

Figure 1. Potential e-government readiness model

Figure 1 sums up the formation of the potential E-Government readiness model. The relationship between ISA and EGOV is explicitly formed in the potential E-Government readiness model, based on DeLone and McLean's' IS Success Model. Moreover, Myers, Kappelman, and Prybutok $^{3}$ point out in their Comprehensive IS Assessment model the importance of the IS assessment model for investigating various issues within the context of the organization and the external environment, such as organizational goals, tasks, structure, volatility, and management philosophy. ITG and IS-ALIGN are components of the organization environment in the model. In turn, the organization environment eventually brings in organizational impact. The relationships among ISA, ITG, IS-ALIGN, and EGOV are hypothesized in the model. As shown in Figure 
1, ISA serves the role of driver, ITG and IS-ALIGN the role of moderator, and EGOV the role of outcome.

\section{PROBLEM STATEMENTS}

Changes in information technology environments are fostering the transformation of organizations. However, despite the enormous investment in IT during recent years, demonstrating the technology effects on organizational performance has proven difficult. The basic assumption of the IS assessment efforts to date is that IS quality and productivity affect organizational performance ${ }^{3,10}$. Yet most proposed models were developed with a focus on an IS perspective, and as a result of such development, reside in an IS-specific domain. Although these models suggest a connection between IS quality and business performance, the IS quality in itself does not ensure organizational success. It appears that the link between the IS function and the other business functions in the organization was not well established in previous IS studies. This study will attempt to establish such a connection through an E-Government readiness model. This study addresses the following two major questions:

1. How can we develop and validate an instrument to assess readiness for E-Government?

2. How can the readiness of the organization, its employees, and technology to accomplish its E-Government initiatives be assessed?

\section{RESEARCH HYPOTHESIS}

The purpose of this study is to assess the readiness of the organization, its employees, and its technology to accomplish its E-Government initiatives by developing and validating an instrument to assess readiness for E-Government. To explore the relationships among IS structure (DeLone and McLean's IS Success model and IS-SERVQUAL), organizational structure (ITG and IS-ALIGN) and readiness for E-Government (EGOV), the study investigates four potential constructs (i.e., ISA, ITG, IS-ALIGN, and EGOV). IS structure is constituted by IS-SUCCESS and IS-SERVQUAL and is collectively referred to as ISA in this study. The purpose of the ISA instrument is to measure the impact of the IS structure on the organization. The dimensions of the ISA instrument include information quality, system quality, service quality, use, user satisfaction, individual impact, and organization impact.

The organizational structure consists of IT governance (ITG) and organization-IS alignment (IS-ALIGN). ITG integrates IT performance in a manner that allows for maximizing benefits, capitalizing on opportunities, 
and gaining competitive advantages. ITG stresses how to govern the business objectives for IT. Organization-IS alignment (IS-ALIGN) addresses both how IT is in harmony with the business, and how the business should, or can be in harmony with IT. IS-ALIGN stresses the relationship between business and IT. The structure of the readiness for E-Government (EGOV) is to investigate how organizations integrate different Internet applications into a coherent and effective business tool at three different levels: the business planning level, the system management level, and the data infrastructure level. EGOV measures the readiness of the organization, its employees, and its technology to accomplish its E-Government initiatives. According to the model designed in the study, the following research hypotheses will be tested:

Hypothesis 1: IT governance impacts IS.

Hypothesis 2: The organization-IS alignment impacts IS.

Hypothesis 3: IS impacts the readiness for E-Government.

Hypothesis 4: There is a connection between IT governance and the organization-IS alignment.

Hypothesis 5: The organization-IS alignment impacts the readiness for E-Government.

Hypothesis 6: IT governance impacts the readiness for E-Government.

\section{METHODOLOGY}

The main objective of the research is to develop effective assessment tools to determine E-Government readiness in an organization-wide and IS specific perspective. It is essential to test whether instruments developed to measure ISA, ITG, IS-ALIGN, and EGOV can be used to measure the readiness for E-Government. It is also necessary to test the relationships among the different instruments (ITG, IS-ALIGN, and ISA) and their relationship to the readiness for E-Government (EGOV). The final goal of the research is to develop a set of guidelines to assist government in transforming itself to better utilizing IT. In order to accomplish this, new instruments developed for measuring ISA, ITG, IS-ALIGN and EGOV are combined into a Web-based survey that is performed in the study. The Web-based survey of the City of Denton (COD) employees about how IT relates to organizational performance was conducted by a research team from the University of North Texas (UNT). There are three main parts (A, $\mathrm{B}$, and $\mathrm{C}$ ) to the survey. The current study utilizes most of the survey except Part A-2 and A-3. The structure of the COD instruments is shown in Table 1. 
Table 1. Structure of the COD instruments

\begin{tabular}{|c|c|c|c|c|}
\hline Contents & Parts & Questions & Total questions & Related questions in the study \\
\hline \multicolumn{5}{|l|}{ Cover Letter } \\
\hline \multicolumn{5}{|l|}{$\begin{array}{ll}\text { Terms } & \& \\
\text { Definition } & \end{array}$} \\
\hline Demographics & A-1 & $1-12$ & 12 & 12 \\
\hline \multirow{2}{*}{ MBNQA } & $\mathrm{A}-2$ & $1-36$ & \multirow{2}{*}{71} & \multirow{2}{*}{ - } \\
\hline & A-3 & $37-71$ & & \\
\hline \multirow{2}{*}{ IS-SERVQUAL } & B-1 & $1-28$ & \multirow[t]{2}{*}{54} & \multirow{2}{*}{54} \\
\hline & B-2 & $29-54$ & & \\
\hline \multirow{2}{*}{$\begin{array}{l}\text { IS-SUCCESS } \\
\text { ITG }\end{array}$} & \multirow[b]{2}{*}{ B-3 } & $1-16$ & 16 & 16 \\
\hline & & $17-27$ & 11 & 11 \\
\hline \multirow{3}{*}{ EGOV } & $\mathrm{C}-1$ & $1-38$ & 38 & - \\
\hline & $\mathrm{C}-2$ & $39-51$ & 13 & 13 \\
\hline & $\mathrm{C}-2$ & $52-63$ & 12 & - \\
\hline IS-ALIGN & $\mathrm{C}-3$ & $1-20$ & 20 & 20 \\
\hline Total & & & 247 & 126 \\
\hline
\end{tabular}

The survey was prepared in multiple pages so that an employee could complete as many or as few pages as they desired at a time. There are three main parts to the survey, so the respondents needed to dedicate approximately three 1-hour sessions of work time to complete the survey. A unique access code was assigned to each employee for security and tracking purposes. The Web server kept track of the progress and guided the employee through the survey. A missing value was not allowed by showing a warning message via a popup window. Duplicates from the same participants were also not allowed, in order to maintain quality responses. The initial e-mail message was sent by the research team to announce the survey, and it provided the user access code. Two more follow-up messages were sent at one-week intervals to encourage participation by those employees who had not completed the survey. To ensure a good response rate and quality responses, the City Council, City Manager, and senior management of the city, and even the teams of focus groups, actively and visibly requested the cooperation of all participating employees. The City Manager sent out two letters to all employees, in which he announced the survey and encouraged their participation. The population of this survey is approximately 1,100 employees of the City of Denton. The data collection was scheduled for a period of five weeks. The response rate of the study was expected to be approximately $30 \%$.

LISREL is an acronym for LInear Structural RELations model. LISREL is considered the most general method for the analysis of causal hypotheses or covariance structure models on the basis of non-experimental data. The study uses the LISREL software to carry out exploratory and 
confirmatory factor analysis, as well as path analysis. There are two basic types of variables in LISREL. In Figure 2 the latent variables are represented by ovals and the observable variables by rectangles. Latent variables are those that are formulated in terms of theoretical or hypothetical concepts, or constructs that are not directly measurable or observable. Observable variables are those that are directly measurable or observable and can be used as indicators of latent variables. In other words, latent variables are represented or measured by observable variables.

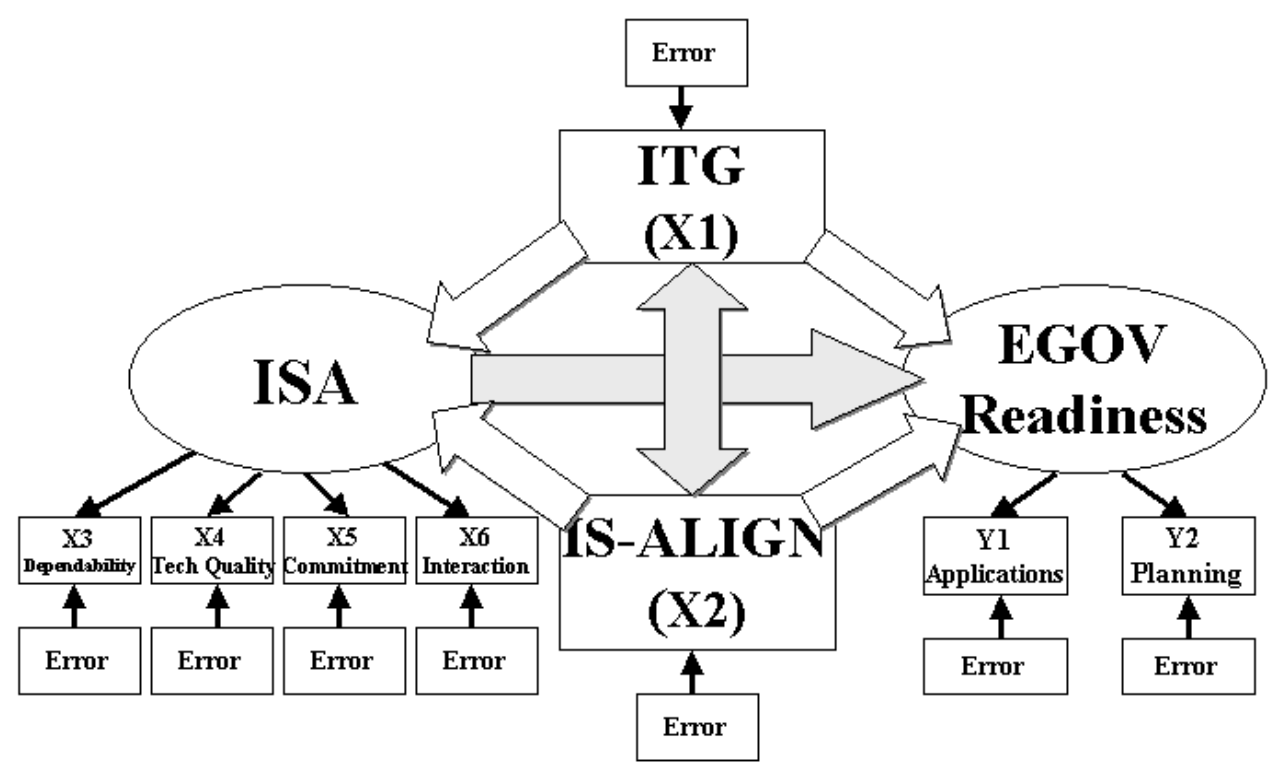

Figure 2. The hypothetical e-government readiness model

Figure 2 demonstrates a hypothetical E-Government readiness model. The constructs on the right side are dependent constructs (e.g., EGOV is the dependent latent construct), and applications and planning are the dependent observable variables. Constructs on the left side are independent constructs (e.g., ISA, ITG, and IS-ALIGN). LISREL integrates both latent theoretical concepts and observed or measured variables into a single structural equation to measure the causal relationship among the constructs. This hypothetical model in Figure 2 states that EGOV is impacted by ITG, IS-ALIGN and ISA. Each of these constructs is a latent construct, which is measured by one or more observable variables.

\section{DATA ANALYSIS AND RESULTS}

At the City of Denton, 1100 email addresses of the employees were used in order to invite them to fill out the on-line survey for this project. A 
total of 339 surveys were submitted, resulting in an initial response rate of $30.82 \%$. Most of the responses were received within a two-week period. Of the on-line surveys submitted, 168 were discarded because they were incomplete (up to $20 \%$ of the values were missing), leaving 171 usable surveys, a $15.55 \%$ final response rate. Although the overall response rate is low, this response rate does not appear to be unusual for on-line surveys.

In the on-line survey, $49 \%$ of the responses were from men, $48 \%$ were from women, and $3 \%$ were missing gender data. The survey was taken by an almost equal number of male and female participants. About $86.4 \%$ of the respondents were between the ages of 25 and 55. There were few workers below 25 or over 55 years of age, less than $5.5 \%$. The average age of the participants was 40.2 . About $80.8 \%$ of the respondents have at least a college degree. About half of the participants have a degree from a four-year college or graduate school, whereas 13\% are high school graduates. These results indicate that the respondents in this study are well qualified to rate the on-line survey.

\subsection{Theoretical Model of E-Government Readiness}

Using the data collected from the COD survey, the research model linking four instruments was tested: ISA, ITG, IS-ALIGN, and EGOV. Figure 3 shows a research model with the indicators to be tested. In this model, the ISA construct consists of four indicators, which are dependability, technical quality, commitment, and interaction. The construct of EGOV consists of two indicators, which are applications and planning. Note that ITG and IS-ALIGN are assumed as a construct in the theoretical model, but they only contain a single indicator that is defined as an observed variable when operating the LISREL program. To sum up, the structural equation modeling (SEM) of this study consists of two latent constructs (ISA and EGOV) with eight indicators: ITG, IS-ALIGN, dependability, technical quality, commitment, interaction, applications, and planning. 


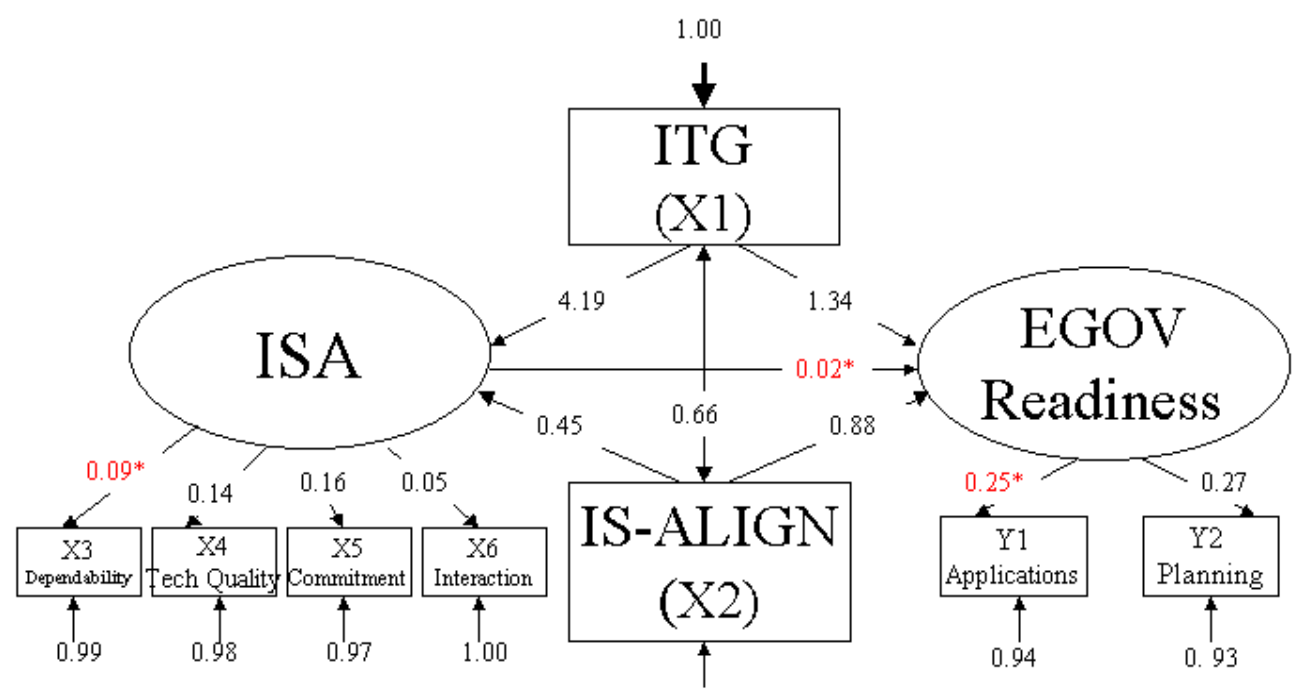

1.00

The path numbers are standardized solution (i.e., standardized coefficients $\beta$ ).

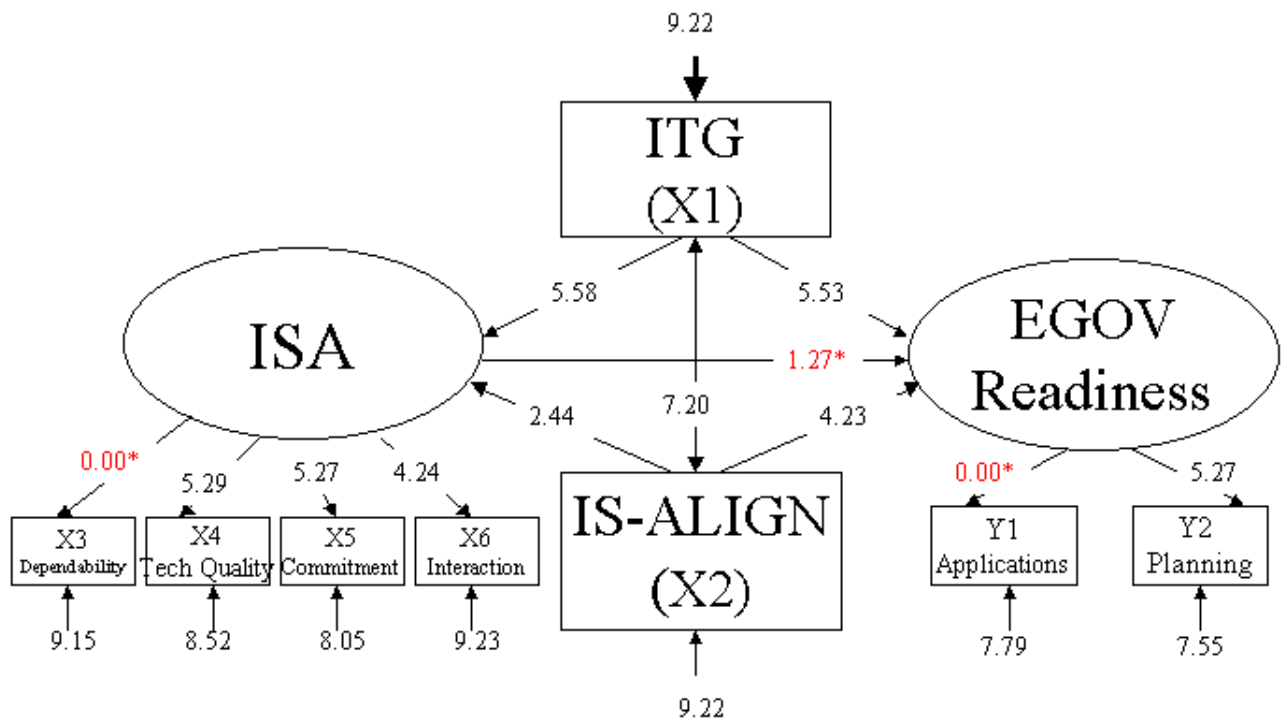

The path numbers are t-values.

Figure 3. Theoretical model of e-government readiness $\left(\mathrm{X}^{2}=38.61, \mathrm{df}=16, \mathrm{p}\right.$-value $=0.00124, \mathrm{RMSEA}=0.091$.

Note that $*$ indicates the path is non-significant.) 
Analysis of the theoretical model results in $\mathrm{X} 2=38.61$, df $=16$, and p-value $=0.00124$, which indicates that the data does not fit the model well. The adjusted goodness-of-fit index (AGFI) value of 0.88 is also nonqualified to the recommended value of 0.9. The root mean square error of approximation (RMSEA) value of 0.09 is under the limit of 0.10 and implies a modest model fit. Overall, the fit indices indicate that the theoretical model does not reproduce the covariance matrix well. Moreover, the path coefficients are examined to determine whether they imply significant relationships between the corresponding constructs. In the theoretical model, most of the coefficients are positive and significant at the $5 \%$ level, except coefficients between EGOV and ISA $(\mathrm{t}=1.27)$, EGOV and Applications $(t=0.00)$, and ISA and Dependability $(t=0.00)$. All these criteria are displayed in the theoretical model. The following two sections will introduce the two modified models (I) and (II), which both consist of good fit indices.

\subsection{Modified Model (I) of E-Government Readiness}

The modified model (I) of E-Government readiness represents a better model fit than the theoretical model; thus, the modified model (I) is proposed as a viable alternative, based on the results of this study (see Figure 4 below). Analysis of the modified model (I) results in $\mathrm{X}^{2}=12.77$, $\mathrm{df}$ $=14$, and $\mathrm{p}$-value $=0.54$ and indicates that the data fit the model. Other indicators also confirm a good fit. The goodness-of-fit index (GFI) of 0.98 indicates that the model fits well because a GFI of 1.0 indicates a perfect fit. The root mean square error of approximation (RMSEA) value of 0.00 is under the limit of 0.10 and implies a good model fit. The adjusted goodness-of-fit index (AGFI) value of 0.95 is above the minimum recommended value of 0.9 . Overall, the fit indices indicate that the first model of the E-Government readiness reproduces the covariance matrix well. Other indications that the model fits the data well are that all standardized residuals are less than 2.0, except one (5.76). Moreover, the path coefficients are examined to determine whether they imply significant relationships between the corresponding constructs. In the modified model (I), most of the coefficients are positive and significant at the 5\% level, except coefficients between EGOV and Applications $(\mathrm{t}=0.00)$, and ISA and Dependability $(\mathrm{t}=0.00)$. All these criteria are displayed in the modified model (I). A good fit of the modified model (I) of E-Government Readiness is shown in Figure 4. 


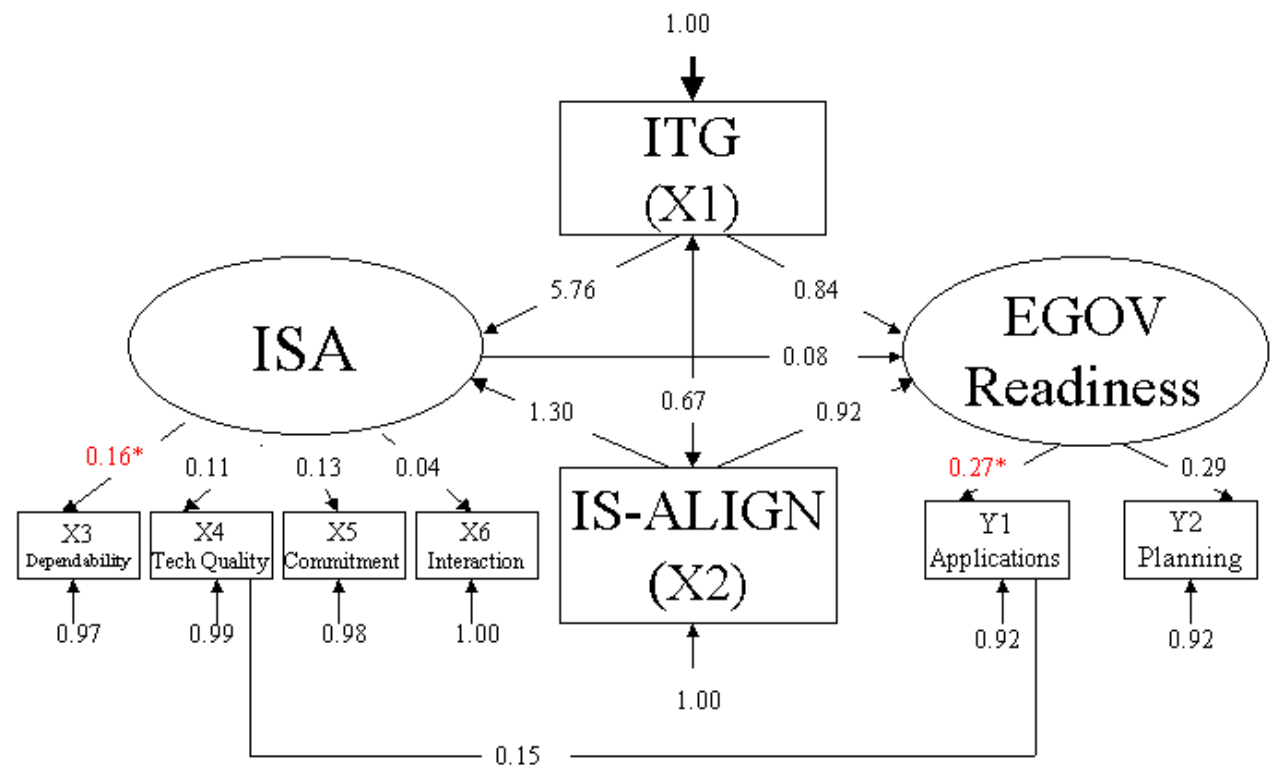

The path numbers are standardized solution (i.e., standardized coefficients $\beta$ ).

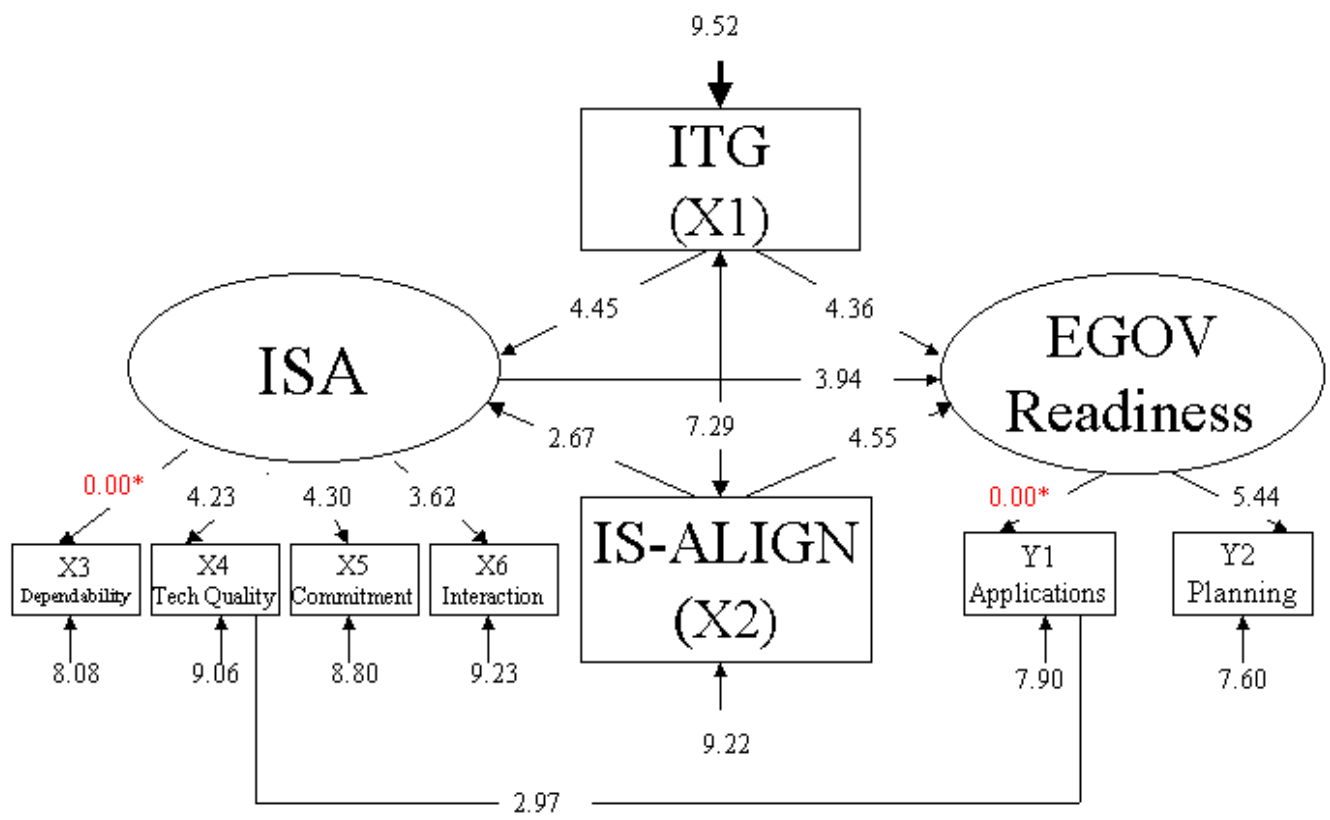

The path numbers are t-values.

Figure 4. Modified model (I) of e-government readiness $\left(X^{2}=12.77, \mathrm{df}=14, \mathrm{p}\right.$-value $=0.54442, \mathrm{RMSEA}=0.000$.

Note that $*$ indicates the path is non-significant.) 


\subsection{Modified Model (II) of E-Government Readiness}

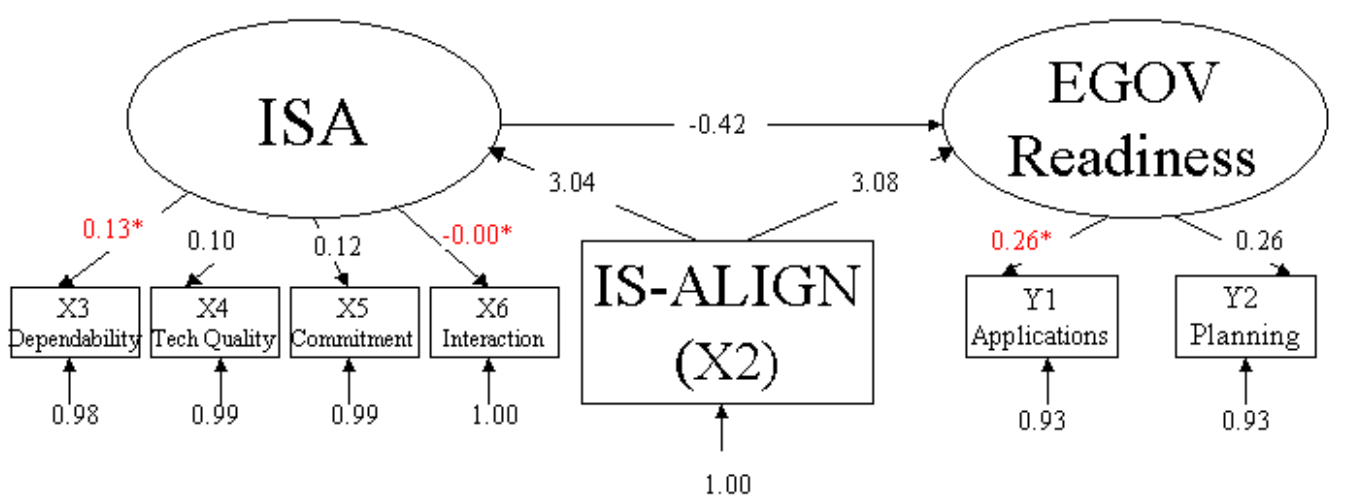

The path numbers are standardized solution (i.e., standardized coefficients $\beta$ ).

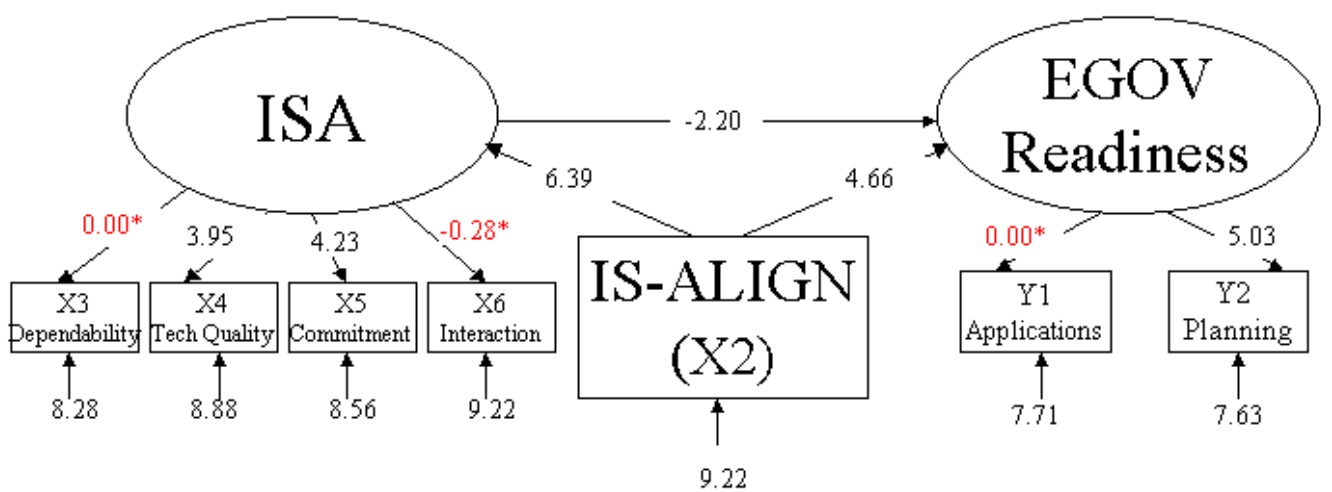

The path numbers are t-values.

Figure 5. Modified model (II) of e-government readiness $(\mathrm{X} 2=12.67, \mathrm{df}=12$, $\mathrm{p}$-value $=0.39322, \mathrm{RMSEA}=0.018$.

Note that $*$ indicates the path is non-significant.)

The modified model (II) of E-Government readiness represents a better model fit than the theoretical model; thus, the modified model (II) is proposed as a viable alternative, based on the results of this study (see Figure 5). Analysis of the modified model (II) results in $\mathrm{X} 2=12.67 \mathrm{df}=12$, and $\mathrm{p}$-value $=0.39$ and indicates that the data fit the model. Other indicators also confirm a good fit. The goodness-of-fit index (GFI) of 0.98 indicates that the model fits well because a GFI of 1.0 indicates a perfect fit. The root mean square error of approximation (RMSEA) value of 0.02 is under the limit of 0.10 and implies a good model fit. The adjusted goodness-of-fit index (AGFI) value is 0.95 , above the recommended value of 0.9. Overall, the fit indices indicate that the modified model (II) also reproduces the covariance matrix well. Moreover, the path coefficients are examined to 
determine whether they imply significant relationships between the corresponding constructs. In the modified model (II), most of the coefficients are positive and significant at the 5\% level, except coefficients between EGOV and Applications $(\mathrm{t}=0.00)$, ISA and Dependability $(\mathrm{t}=$ $0.00)$, and ISA and Interaction $(t=-0.28)$. All these criteria indicate the modified model (II) is a good fit. Note that ISA impacts EOGV directly, but negatively, in the model. This feature is different from other models. The modified model (II) of E-Government readiness is shown in Figure 5.

\section{CONCLUSION AND FINDINGS}

A number of findings related to IS, IT governance, organization-IS alignment, and readiness for E-Government are identified in this study. The findings are summarized for each hypothesis that is investigated in this study.

Hypothesis 1: IT governance impacts IS (i.e., ITG -> ISA).

Results of this study indicate partial support for hypothesis 1. The partial support means that if the hypothesis exists, it needs to meet certain conditions. The findings of this study indicate that ITG impacts IS. The hypothesis only exists in the entire model that contains other constructs such as IS-ALIGN and EGOV based on the modified E-Government model (II). The impact from ITG to IS is primarily on technical quality, the commitment of the staff to support user involvement, and the interaction of the customers and staff. If ITG predicts IS alone without other constructs, the hypothesis will not apply.

Hypothesis 2: Organization-IS alignment impacts IS (i.e., IS-ALIGN -> ISA).

Results of this study indicate strong support for hypothesis 2. The findings of this study indicate that IS-ALIGN predicts ISA well in both the entire and partial models. This finding suggests that organization-IS alignment has a direct impact on IS. The impact from organization-IS alignment to IS is primarily on technical quality, the commitment of the staff to support user involvement, and the interaction of the customers and staff.

Hypothesis 3: IS impacts the readiness for E-Government (i.e., ISA -> EGOV).

Results of this study indicate support for hypothesis 3 . The findings of this study reveal that ISA predicts EGOV in the entire model, but has only a modest fit in the partial model. This finding suggests that IS has impact on how an organization uses IT directly, especially in the entire model with ITG and ALIGH constructs together. The scope of IS consists of IS service 
quality, the commitment of the staff to support user involvement, and the interaction of the customers and staff. The scope of readiness for E-Government is assessed at the planning and application levels.

Hypothesis 4: There a connection between IT governance and organization-IS alignment (i.e., ITG <-> IS-ALIGN).

Results of this study indicate strong support for hypothesis 4. ITG predicts IS-ALIGN or IS-ALIGN predicts ITG well in both of the entire and partial models. The finding of this study suggests that there is a connection between how an organization controls its objectives for IT, and how it directly aligns IT and the business. Another finding of this study is that ITG and IS-ALIGN have correlated and bi-directional relationships, rather than a causal relationship.

Hypothesis 5: Organization-IS alignment impacts the readiness for E-Government (i.e., IS-ALIGN -> EGOV).

Results of this study indicate strong support for hypothesis 5. The findings of this study indicate that IS-ALIGN predicts EGOV positively in both the entire and partial models. The finding suggests that organization-IS alignment impacts how an organization uses IT positively. The scope of readiness for E-Government is assessed at the planning and application levels.

Hypothesis 6: IT governance impacts the readiness for E-Government (i.e., ITG ->EGOV).

Results of this study indicate strong support for hypothesis 6 . The findings of this study reveal that ITG predicts EGOV positively in both of the entire and partial models. This result suggests that controlling business objectives for IT has impact on how an organization uses IT directly. The scope of readiness for E-Government is assessed at the planning and application levels. The summary of support for the study's hypotheses is shown in Table 2.

\subsection{Recommendations for Future Research}

Future research into readiness for E-Government should investigate ways to study relationships among the four instruments of ISA, ITG, IS-ALIGN and EGOV, or ways to study relationships among subsets of these instruments. Further theory development and the associated instrument refinement, and model validation are also necessary. Based on the results of this study, there exist two modified E-Government readiness models (I \& II), which represent good model fits. In the modified model (I), ISA may be better represented by three dimensions reflecting technical quality, commitment to user involvement, and interaction between the staff and 
customers. EGOV may be better assessed by the strategic or planning stage. ITG and IS-ALIGN may be better represented by one dimension only. The result of the path analysis suggests that ITG is more important than IS-ALIGN and ISA in affecting EGOV. The order of the importance in affecting EGOV is ITG, IS-ALIGN and ISA in the modified model (I). The result of LISREL estimates suggests that the best structural equation is $\mathrm{EGOV}=1.33 * \mathrm{ITG}+0.84 * \mathrm{IS}-\mathrm{ALIGN}$.

Table 2. Summary of support for hypotheses

\begin{tabular}{llll}
\hline Hypothesis & $\begin{array}{l}\text { Entire Model } \\
\text { (i.e., } \\
\text { Modified I) }\end{array}$ & $\begin{array}{l}\text { Partial } \\
\text { Model }\end{array}$ & Conclusion \\
\hline 1. IT governance impacts IS. (ITG->ISA) & $\begin{array}{l}\text { Reject } \mathrm{H}_{0} \& \\
\text { Accept } \mathrm{H}_{1}\end{array}$ & $\begin{array}{l}\text { Not } \\
\text { converged }\end{array}$ & $\begin{array}{l}\text { Partial } \\
\text { support }\end{array}$ \\
\hline $\begin{array}{l}\text { 2. Organization-IS alignment impacts IS. } \\
\text { (IS-ALIGN->ISA) }\end{array}$ & $\begin{array}{l}\text { Reject } \mathrm{H}_{0} \& \\
\text { Accept } \mathrm{H}_{1}\end{array}$ & Good fit & $\begin{array}{l}\text { Strong } \\
\text { support }\end{array}$ \\
\hline $\begin{array}{l}\text { 3. IS impacts the readiness for } \\
\text { E-Government. (ISA->EGOV) }\end{array}$ & $\begin{array}{l}\text { Reject } \mathrm{H}_{0} \& \\
\text { Accept } \mathrm{H}_{1}\end{array}$ & Modest fit & Support \\
\hline $\begin{array}{l}\text { 4. There a connection between IT } \\
\text { governance and organization-IS alignment. } \\
\text { (ITG->IS-ALIGN) }\end{array}$ & $\begin{array}{l}\text { Reject } \mathrm{H}_{0} \& \\
\text { Accept } \mathrm{H}_{1}\end{array}$ & Perfect fit & $\begin{array}{l}\text { Strong } \\
\text { support }\end{array}$ \\
\hline $\begin{array}{l}\text { 5. Organization-IS alignment impacts the } \\
\text { readiness for E-Government. } \\
\text { (IS-ALGIN->EGOV) }\end{array}$ & $\begin{array}{l}\text { Reject } \mathrm{H}_{0} \& \\
\text { Accept } \mathrm{H}_{1}\end{array}$ & Perfect fit & $\begin{array}{l}\text { Strong } \\
\text { support }\end{array}$ \\
\hline $\begin{array}{l}\text { 6. IT governance impacts the readiness for } \\
\text { E-Government. (ITG->EGOV) }\end{array}$ & $\begin{array}{l}\text { Reject } \mathrm{H}_{0} \& \\
\text { Accept } \mathrm{H}_{1}\end{array}$ & Perfect fit & $\begin{array}{l}\text { Strong } \\
\text { support }\end{array}$ \\
\hline
\end{tabular}

In hypothesis 1 in the partial model, the relationship between ISA and ITG did not converge, so the modified model (II) only investigated relationships among the three instruments ISA, IS-ALIGN and EGOV. In the modified model (II), ISA may be better represented by technical quality, and by attitude or commitment to user involvement. EGOV may be better assessed only by the planning stage. ITG should be omitted in order to improve the model fit. IS-ALIGN may be better represented by one dimension. The result of the path analysis suggests that IS-ALIGN is more important than ISA in affecting EGOV. The result of LISREL estimates suggests that the best structural equation is EGOV $=1.87 *$ IS-ALIGN. In addition, ISA impacts EGOV directly, but negatively, in the model (II). This feature is different from other models, so it may need further research in the future. A proposed two models of E-Government readiness, incorporating the results of this study, is shown in Figures 6 and 7. 


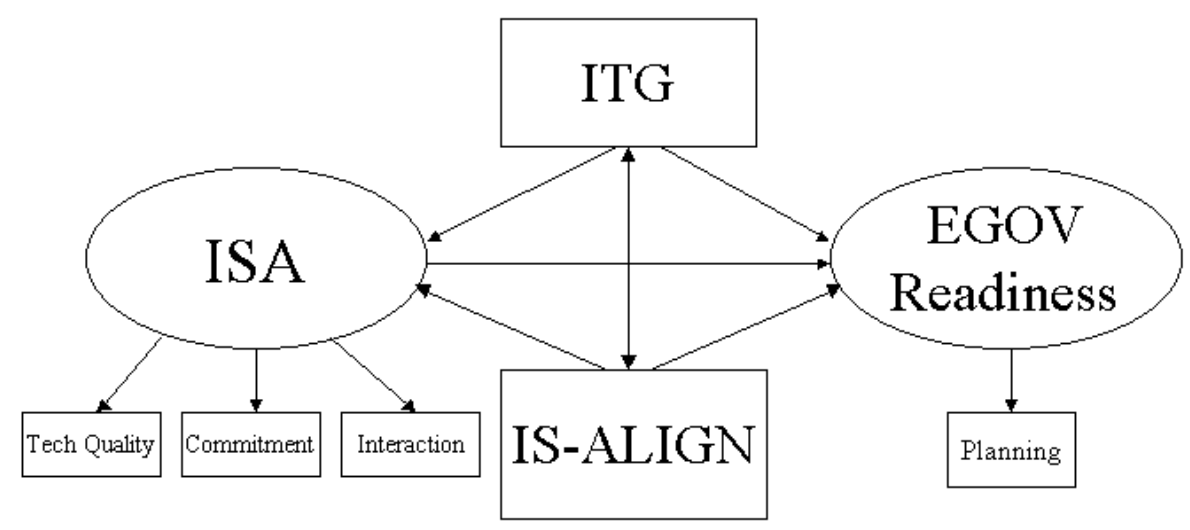

Figure 6. Proposed model (I) of e-government readiness

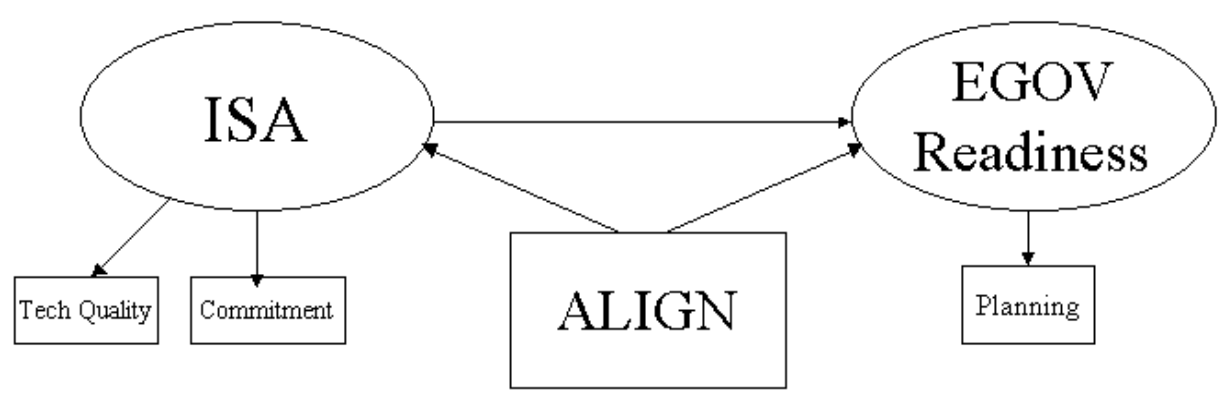

Figure 7. Proposed model (II) of e-government readiness

The ISA instrument as used in this work was the result of combing two instruments, IS-SERVQUAL and IS-SUCCESS. Though a 0.5 and 0.5 loading rule was justified for the preliminary instrumentation development work undertaken in this work, future work should carefully examine options such as using a 0.5 and 0.4 rule or even a 0.5 and 0.3 rule. Combining IS-SERVQUAL and IS-SUCCESS into one instrument is one approach that was pursued based on the theory as presented in this study. However, separating the two instruments, IS-SERVQUAL and IS-SUCCESS, and examining their relationship, is another potentially justifiable approach. In addition, forcing three factors in the factor analysis for the ISA instrument may result in different dimensions that may fit theoretical models other than the one proposed by Myers, Kappelman, and Prybutok ${ }^{8}$. Future research merits using such different approaches with new data sets. 


\subsection{Implications}

The study uncovered evidence that various instruments developed to measure ISA, ITG, IS-ALIGN and EGOV should be combined to more effectively measure readiness for E-Government. Results of this study indicate that although a number of factors contribute to IS assessment (such as dependability, technical quality, commitment, and interaction), attitude is one of the most important factors, based on the results of the two modified models. The commitment of the staff to support user involvement and participation in IS development is crucial to readiness of E-Government. To assess E-Government readiness, the most important stage is the strategic or planning level. An organization prepares for E-Government by devising enterprise-wide E-Government strategies in line with business strategies and plans which indicate it is in a critical period. At this stage, the organization should be aware of the strategic importance of E-Government and should regard E-Government initiatives as integral parts of overall business plans.

\subsection{Contribution to Literature}

Although the two modified models widely accepted the theoretical hypotheses, the confirmation of the relationships among constructs still needs researchers to pursue more reliable models either by replication of this research or by establishing a new theoretical model. However, the significant validity and reliability measures discussed in this study indicate that the instrument of this E-Government readiness model has the potential for use in further adoption studies.

\section{REFERENCES}

[1] D. Patterson, and W. Hanson, 21st century government: Principles for transformation. Government Technology. Retrieved on April 18, 2001, from http://www.erepublic.com/publications/21stCentury/intro.phtml.

[2] A.M. Sharif, Z. Irani, and V. Weerakkoddy, Evaluating and modeling constructs for e-government decision making. The Journal of the Operational Research Society, 61(6), p929-953, 2010. doi:10.1057/jors.2010.11.

[3] T.P. Van Dyke, L.A., Kappelman, and V.R. Prybutok, Measuring information systems service quality: Concerns on the use of the SERVQUAL questionnaire. MIS Quarterly, 21(2), p195-208, 1997. doi:10.2307/249419.

[4] T. Van Dyke, V. Prybutok, and L. Kappelman, Cautions on the use of the SERVQUAL measure to assess the quality of information systems services. Decision Sciences, 30(3), p877-891, 1999. 
[5] W.H. DeLone, and E.R. McLean, Information systems success: The quest for the dependent variable. Information Systems Research, 3(1), p60-95, 1992. doi:10.1287/isre.3.1.60.

[6] Malcolm Baldrige National Quality Award (MBNQA). U.S. Department of Commerce, 1987. Retrieved October 18, 2011, from http://asq.org/learn-about-quality/malcolm-baldrige-award/overview/ov erview.html.

[7] C.E. Koh, and P. Balthazard, Electronic commerce and the World Wide Web: A framework of business Web use and a study of business Web practices, 1997.

[8] B. Myers, L. Kappelman, and V. Prybutok, A comprehensive model for assessing the quality and productivity of the information systems functions: Toward a theory for information systems assessment. In E. Garrity \& L. Sanders (Eds.), Information System Success Measurement (p 94-121). Harrisburg, PA: Idea Group, 1998.

[9] L. Kappelman, and H. Chong, The City of Denton (COD) Project: The IS-SUCCESS Instrument, 2001.

[10] A. Parasuraman, A.V, Zeithaml, and L.L. Berry, SERVQUAL: A multiple-item scale for measuring user perceptions of service quality. Journal of Retailing, 64(1), p12-40, 1988.

[11] A. Sanchez, and L. Kappelman, The City of Denton (COD) Project: The Information Technology Governance (ITG) Instrument, 2001.

[12] Control Objectives for Information and related Technology (COBIT), The COBIT Steering Committee and the IT Governance Institute ${ }^{T M}$, 2000. Retrieved October 18, 2011, from http://www.isaca.org/Knowledge-Center/COBIT/Pages/Overview.asp.

[13] J.C. Henderson, and N. Venkatraman, Strategic alignment: Leveraging information technology for transforming organizations. IBM Systems Journal, 32(1), p4-16, 1993. doi:10.1147/sj.382.0472.

[14] A. Sanchez, and L. Kappelman, The City of Denton (COD) Project: The Information System Alignment (IS-ALIGN) Instrument, 2001. 
